\title{
ESGOTAMENTO DAS RESERVAS NA SEMENTE DE EUTERPE EDULIS MART. E EFEITO DA NUTRIÇÃO MINERAL NAS PLÂNTULAS
}

\author{
Silvia Venturi' \\ Maria Terezinha Silveira Paulilo'
}

Recebido em 12/03/1997. Aceito em 16/11/1998

\begin{abstract}
RESUMO - (Esgotamento das reservas na semente de Euterpe edulis Mart. e efeito da nutrição mineral nas plântulas). As reservas da semente de Euterpe edulis. crescendo em substrato composto de argila, areia e adubo orgânico, na proporção de 2:1:2. esgotaram-se quando a plântula apresentou as duas primeiras folhas fotossintetizantes expandidas. podendo ser esta a causa da grande mortalidade no campo de plântulas que já desenvolveram a terceira folha. Aumento na adubação não refletiu em aumento de massa seca ou área foliar de plantas nos primeiros cinco meses de crescimento. Plantas mais velhas, entretanto, apresentaram aumento de massa seca da parte aérea com a adição de solução nutritiva ao substrato.
\end{abstract}

Palavras-chave - Euterpe edulis, nutrição mineral, reservas da semente

\begin{abstract}
Seed reserves mobilization in Euterpe edulis Mart. and effect of mineral nutrition in seedlings). The seed reserves of Euterpe edulis finished when the seedlings showed the $2^{\text {nd }}$ green leaf completely expanded. This fact could be the cause of the great mortality observed in field conditions by seedlings showing the $3^{\text {nd }}$ green leaf. Seedlings of Euterpe edulis, until age of five months, did not present higher growth under higher nutrition. Older seedlings, however, presented higher shoot dry weight when Hoagland solution was added.
\end{abstract}

Key words - Euterpe edulis, mineral nutrition, seed reserves

\section{Introdução}

Euterpe edulis (palmiteiro) é uma das espécies da Floresta Atlântica que mais vem sofrendo a ação extrativista desordenada, devido ao seu alto valor econômico como alimento (Floriano et al. 1988). Isto vem comprometendo tanto o equilíbrio ecológico, já que $E$. edulis mantém vários níveis de interação com a fauna, como a potencialidade econômica da espécie (Reis et al. 1991). A instalação e manutenção de plantações de palmiteiros ou o extrativismo auto-sustentável, em populações naturais, necessita de estudos sobre o plantio, bem como sobre particularidades do desenvolvimento da espécie.

Universidade Federal de Santa Catarina, CCB. Departamento de Botânica, Campus Universitário. Trindade, C. Postal 476. CEP 88.040-900, Florianópolis. SC. Brasil 
Sementes de E. edulis possuem endosperma muito abundante, com alto teor de reservas, as quais constituem-se de carboidratos (cerca de $88 \%$ ), proteínas (10\%) e lípides (2\%) (Reis 1995). Alto teor de reservas em sementes permite o estabelecimento de plântulas em condições ambientais não satisfatórias (Leishman \& Westoby 1994). Silva (1991) sugeriu que as reservas da semente de E. edulis devem manter o crescimento da plântula em condições desfavoráveis de luminosidade até o surgimento da terceira folha, uma vez que, após este estádio, há alta mortalidade de plântulas no campo.

A sobrevivência das plântulas também está ligada às condições de fertilidade do solo. Neste aspecto, é de interesse o estudo do comportamento de plântulas de E. edulis sob diferentes níveis nutricionais.

Neste trabalho procurou-se verificar a época de esgotamento das reservas na semente de $E$. edulis e a influência de diferentes níveis de nutrição do substrato durante o crescimento inicial da planta.

\section{Material e métodos}

Plântulas de E. edulis, obtidas através da germinação de frutos despolpados (caroço), correspondendo a endocarpo mais semente, foram submetidas a diferentes condições de crescimento.

Para o experimento de translocação de reservas da semente, as plântulas com epicótilo de cerca de $3 \mathrm{~cm}$ foram plantadas em sacos plásticos de $7 \mathrm{~cm}$ de diâmetro e $20 \mathrm{~cm}$ de altura, contendo argila, areia e adubo orgânico na proporção de 2:1:2, e colocadas para crescer sob tela sombrite com $30 \%$ de corte de luz por seis meses. Para possibilitar a generalização dos dados obtidos neste experimento, optou-se pelo uso de estádios de crescimento e não da idade da plântula, uma vez que a idade do indivíduo não representa, necessariamente, o seu estádio de desenvolvimento, podendo a relação estádio/idade variar em diferentes condições ambientais (Gatsuk et al. 1980). Foram determinados os seguintes estádios de crescimento: estádio 0: semente não germinada; estádio 1: plântula com epicótilo de $3 \mathrm{~cm}$; estádio 2 : plântula com a $1^{\mathrm{a}}$ folha completamente fechada; estádio 3: plântula com a $1^{\text {a }}$ folha parcialmente expandida; estádio 4: plântula com a $1^{\mathrm{a}}$ folha expandida; estádio 5: plântula com a $1^{\mathrm{a}}$ folha expandida e a $2^{\mathrm{a}}$ folha fechada; estádio 6 : plântula com 2 folhas expandidas e a $3^{\mathrm{a}}$ folha fechada. Foram tomadas medidas de massa seca de raiz, parte aérea e caroço de nove plantas de cada estádio de crescimento, de 1 a 6. No estádio 0 , correspondente à semente não germinada, a massa seca determinada foi equivalente à média de 50 caroços, considerando-se desprezível a massa seca do embrião $(<1 \mathrm{mg})$. Foram consideradas folhas, como em Silva (1991), apenas aquelas fotossintetizantes, verdes e palmadas, não se computando como tais as duas folhas carmináceas, rudimentares, não fotossintetizantes que surgem antes da primeira folha fotossintetizante.(Belin \& Queiroz 1988).

Para avaliar o efeito de diferentes níveis de nutrição do substrato sobre o crescimento de plantas, foram feitos dois experimentos. No primeiro, plântulas com epicótilo de aproximadamente $1 \mathrm{~cm}$, foram colocadas em sacos plásticos de $7 \mathrm{~cm}$ de diâmetro, $20 \mathrm{~cm}$ de altura, contendo argila, areia e adubo orgânico na proporção de 2:1:2 (substrato 1), ou na proporção de 2:1:4 (substrato 2) e postas para crescer sob tela sombrite de $30 \%$ de corte de luz. Após cinco mreses de crescimento, nove plântulas 
crescidas em cada um destes substratos foram analisadas para medidas de massa seca e área foliar. Num segundo experimento, plantas com seis meses de idade, crescidas no substrato 2, remanescentes do primeiro experimento, foram separadas em dois grupos: um deles foi irrigado, a cada 15 dias, com solução de Hoagland completa a 100\% (Hoagland e Arnon 1938) até percolação; entre as irrigações com solução nutritiva as plantas foram irrigadas com água; o outro grupo foi irrigado apenas com água. As plantas permaneceram sob sombrite de $30 \%$ de corte de luz e após mais seis meses de crescimento nestas condições, foram coletadas nove plantas de cada um dos grupos, tomando-se a medida de massa seca e área foliar.

A massa seca foi obtida através da pesagem do material seco a $80^{\circ} \mathrm{C}$ por $48 \mathrm{~h}$ (Chiarello et al. 1992). A área foliar foi obtida através da comparação do peso das folhas desenhadas em papel com o peso de áreas conhecidas do mesmo papel (Godoy \& Felippe 1992).

A comparação dos resultados foi feita através do teste de Student, segundo Snedecor \& Cochram (1967).

\section{Resultados e discussão}

Observa-se, pela Fig. 1, que a massa seca total da plântula (embrião, mais endosperma, tegumento da semente e endocarpo) diminui até o surgimento da primeira folha (estádio 2), devido à perda de matéria seca pela respiração e ausência de fotossíntese

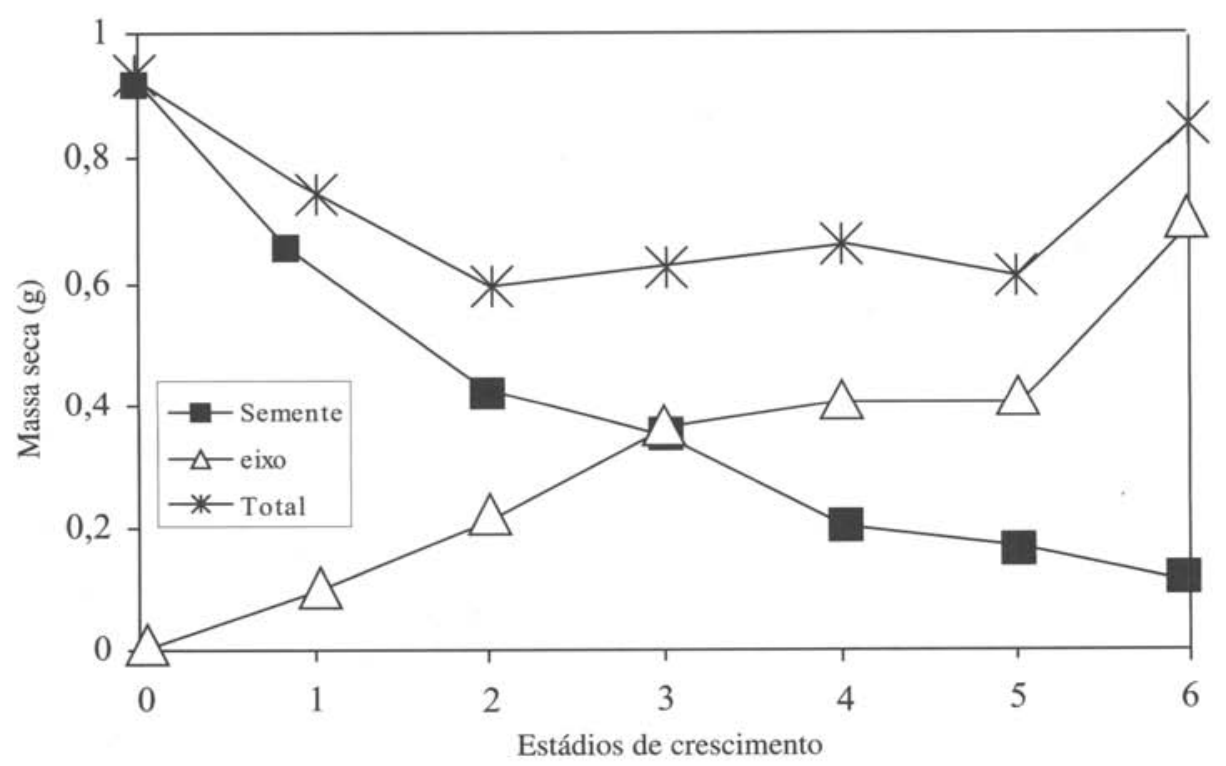

Figura 1. Massa seca do conjunto endocarpo-tegumento da semente-endosperma, do eixo embrionário, e total de plântulas de Euterpe edulis nos diferentes estádios de crescimento. (Conjunto endocarpo-tegumento da semente-endosperma $\mathbf{a}$, Eixo embrionário $\Delta$, total $*$ ) 
neste período. $\mathrm{O}$ crescimento do eixo embrionário (raiz mais parte aérea), nesta fase, deve-se unicamente à translocação das reservas do endosperma A produção de matéria seca pela fotossíntese iguala-se à matéria seca respirada entre os estádios 2 e 5 de crescimento, e só a partir do estádio 5 , já com o aparecimento da $2^{\mathrm{a}}$ folha, é que a produção fotossintética sobrepuja a matéria gasta na respiração, levando a um crescimento de matéria seca total. Observa-se, também, que a maior perda da massa seca do conjunto endocarpo - tegumento - endosperma, cerca de $60 \%$, dá-se até o estádio 2 de crescimento (ao redor de 45 dias após a germinação). A partir daí a perda de massa seca ocorre mais vagarosamente, sendo que no estádio 6 (ao redor de 6 meses de crescimento) a massa seca deste conjunto corresponde apenas ao endocarpo e tegumento da semente. Assim, quando a plântula apresenta duas folhas expandidas, as reservas da semente já estão completamente exauridas.

Na Fig. 2 observa-se que a distribuição de matéria seca é maior para a raiz enquanto a plântula ainda não apresenta folhas (estádio 1). Entre os estádios 1 e 2 de crescimento, raiz e parte aérea apresentam massa seca equivalentes; entretanto, ainda antes da plântula ter expandido a primeira folha, entre os estádios 2 e 3 de crescimento, a parte aérea já apresenta o dobro da massa seca da raiz.

Os dados deste trabalho indicam que, no estádio 6 de crescimento, antes da terceira folha estar expandida, as reservas da semente estavam exauridas, reforçando a hipótese de Silva (1991) de que, em campo, sem possibilidade de fotossíntese satisfatória, a

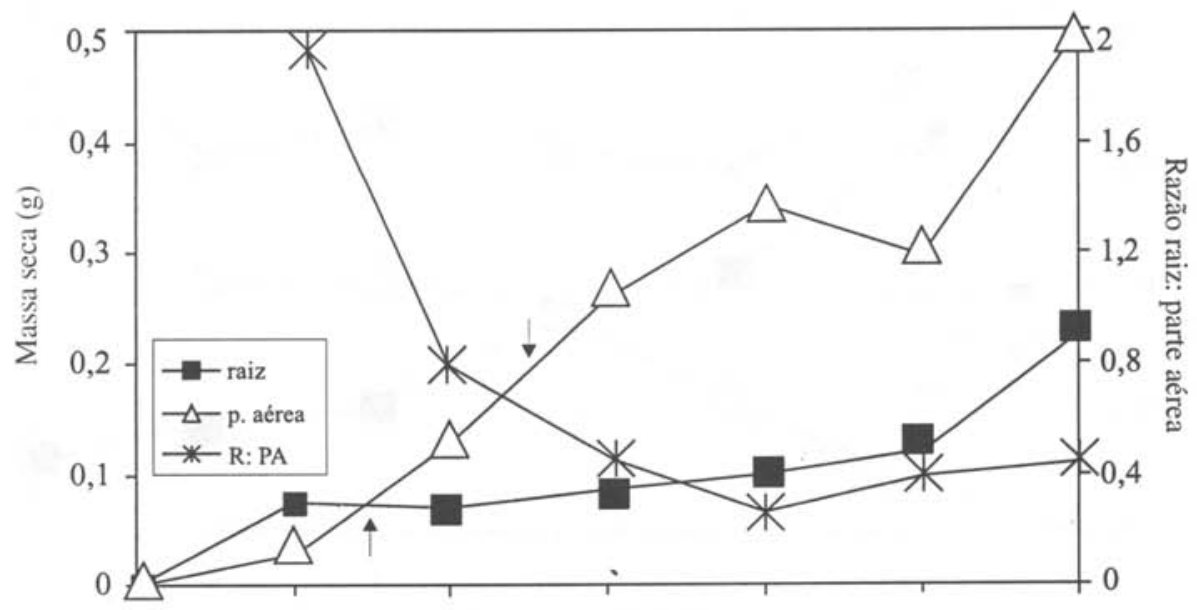

Estádios de crescimento

Figura 2. Massa seca de raiz e parte aérea e razão entre raiz e parte aérea de plântulas de Euterpe edulis nos diferentes estádios de crescimento. (Raiz $\mathbf{E}$, Parte aérea $-\Delta$, razão raiz: parte aérea $-*$ ). ( $\uparrow$ )ponto em que raiz e parte aérea apresentam massa seca equivalentes, $(\downarrow)$ ponto em que a parte aérea apresenta o dobro da massa seca da raiz. 
causa da grande mortalidade de plântulas, verificada por volta do surgimento da terceira folha, seria devido ao esgotamento das reservas da semente.

Os resultados obtidos com diferentes níveis de adubação orgânica mostraram que plantas de $E$. edulis crescendo, por cinco meses, no substrato 1 (menor nível nutricional) ou no substrato 2 (maior nível nutricional) apresentaram peso seco total e área foliar similares, cerca de $0,4 \mathrm{~g} \mathrm{e} 30 \mathrm{~cm}^{2}$ respectivamente. $O$ valor da razão raiz:parte aérea também foi semelhante, nos dois níveis nutricionais experimentados, estando ao redor de 0,5 .

Aguiar et al. (1996) também não obtiveram aumento de crescimento de E. edulis com aumento de adubação nitrogenada, concluindo que o substrato utilizado, solo de mata, já continha a quantidade de nitrogênio necessária ao desenvolvimento de mudas.

Entretanto, plantas com seis meses de idade, crescidas no substrato 2 e, então, irrigadas com solução nutritiva por mais seis meses, apresentaram, em relação às plantas controle, irrigadas apenas com água, aumento de massa seca da parte aérea (Tab. 1). A razão raiz:parte aérea foi menor em plantas irrigadas com solução nutritiva em relação às plantas irrigadas apenas com água, sendo os valores, respectivamente de 0,40 e 0,57.

Tabela 1. Massa seca e área foliar de plantas de Euterpe edulis após 12 meses de crescimento no substrato 2. irrigadas apenas com água ou com solução nutritiva de Hoagland $100 \%$, a partir de seis meses de crescimento.

\begin{tabular}{|c|c|c|c|c|c|}
\hline \multirow[b]{2}{*}{ Substratos } & \multicolumn{4}{|c|}{$\begin{array}{c}\text { Peso seco } \\
(\mathrm{g})\end{array}$} & \multirow[t]{2}{*}{$\begin{array}{c}\text { Área foliar } \\
\left(\mathrm{cm}^{2}\right)\end{array}$} \\
\hline & Raiz & Lâmina foliar & Parte aérea & Total & \\
\hline Substrato 2 & $1,85 \mathrm{a}$ & $1,70 \mathrm{a}$ & $3,25 \mathrm{a}$ & $5,10 \mathrm{a}$ & $47,0 \mathrm{a}$ \\
\hline $\begin{array}{l}\text { Substrato } 2+ \\
\text { sol. nutritiva }\end{array}$ & $1.89 \mathrm{a}$ & $2,40 \mathrm{~b}$ & $4.90 \mathrm{~b}$ & $6.79 b$ & $53,0 \mathrm{a}$ \\
\hline
\end{tabular}

Estes dados parecem indicar que, nos estádios iniciais de crescimento de E. edulis, uma adubação complementar não seria necessária, uma vez que aumento de adubação aplicado durante os primeiros cinco meses após o plantio não refletiu em aumento de massa seca ou área foliar das plantas. Plantas mais velhas, entretanto, apresentaram aumento da massa seca de parte aérea quando solução nutritiva foi adicionada ao substrato, indicando que complementação nutricional pode ser necessária em estádios não iniciais de crescimento de plantas de E. edulis.

\section{Agradecimentos}

Ao CNPq pela bolsa de aperfeiçoamento concedida a Silvia Venturi durante a realização desta pesquisa. A Ana Cristina Segalin de Andrade pelo auxílio na coleta de dados. 


\section{Referências bibliográficas}

Aguiar, F. A. A.: Kanashiro, S. \& Barbedo, C. 1996. Influência do sombreamento e da adubação nitrogenada na formação de mudas de Euterpe edulis Mart. (Palmiteiro). Pp. 473. In XLVII Congresso Nacional de Botânica, Nova Friburgo.

Belin. M. \& Queiroz, M. H. de. 1988. Contribuição ao estudo ontogênico das palmeiras. Alguns aspectos da germinação de Euterpe edulis Mart. p. 211-213. Anais do $1^{2}$ Encontro Nacional de Pesquisadores em Palmito. Embrapa, Curitiba.

Chiarello, N. R.; Mooney, H. A. \& Willians, K. 1992. Growth. carbon allocation and cost plant tissue. Pp. 327-364. In K. W. Pearcy; R. Ehleringer; H. A. Mooney \& P. W. Rudel (eds), Plant Phisyological Ecology. Chapman \& Hall. New York.

Floriano, E. P.; Nodari, R. O.; Reis, A.; Reis, M. S. \& Guerra. M. P. 1988. Manejo do palmiteiro, uma proposta. Pp. 189-194. In Anais do $1^{2}$ Encontro Nacional de Pesquisadores em Palmito. Embrapa, Curitiba.

Gatsuk, E.; Smirnova, O. V.; Vorontzova, L. I.; Zaugolnova. L. B. \& Zhukova, L. A. 1980. Age states of plants of various growth forms: a review. Journal of Ecology 68: 675-696.

Godoy, S. M. A. de \& Felippe, M. G. 1992. Crescimento inicial de Qualea cordata, uma árvore do cerrado. Revista Brasileira de Botânica 14: 23-30.

Hoagland, D. R. \& Arnon. D. I. 1938. The water culture method for growing plants without soil. University of California Agricultural Experimental Station, circular n. 347.

Leishman, M. R. \& Westoby, M. 1994. The role of large seed size in shaded conditions: experimental evidence. Functional Ecology 8: 205-214.

Reis. A. 1995. Dispersão de sementes de Euterpe edulis Martius (Palmae) em uma floresta ombrófila densa montana da encosta atlântica em Blumenau, SC. Tese de Doutorado. UNICAMP, Campinas.

Reis. A.: Reis, M. S. \& Fantini. A. C. 1991. O palmiteiro como um modelo de manejo em rendimento sustentado. Higiene Alimentar 5: 27-31.

Silva. D. M. 1991. Estrutura de tamanho e padrão espacial de uma população de Euterpe edulis Mart. (Arecaceae) em mata mesófila semidecídua no município de Campinas, SP. Dissertação de Mestrado. UNICAMP, Campinas.

Snedecor, G. W. \& Cochram. W. G. 1967. Statistical Methods. Iowa State University Press, Iowa. 